Curr Opin Hematol. 2008 May ; 15(3): 162-168. doi:10.1097/MOH.0b013e3282fa7470.

\title{
APLASTIC ANEMIA
}

Neal S. Young, Phillip Scheinberg, and Rodrigo T. Calado

Hematology Branch, National Heart, Lung, and Blood Institute, National Institutes of Health Bethesda, MD 20892

\section{Abstract}

Purpose of review-Most acquired aplastic anemia (AA) is the result of immune-mediated destruction of hematopoietic stem cells causing pancytopenia and an empty bone marrow, which can be successfully treated with either immunosuppressive therapy (IST) or hematopoietic stemcell transplantation (HSCT).

Recent findings-In AA, oligoclonally expanded cytotoxic T-cells induce apoptosis of hematopoietic progenitors. T-bet, a transcription factor that binds to the interferon- $\gamma$ promoter region, is up-regulated in AA T-cells. Regulatory T-cells are significantly reduced in patients' peripheral blood and in an AA murine model, infusion of regulatory T-cells ameliorates disease progression. In a minority of cases, loss-of-function mutations in telomerase complex genes may underlie disease development. Long term survival, once strongly linked to response to immunosuppressive therapy, can now be achieved even among non-responders due to significant advances in supportive care and better salvage treatments.

Summary-Evidence has accumulated in the recent years further corroborating an immunemediated process underlying AA pathogenesis. HSCT from a matched sibling donor is preferred for children and young adults with severe AA, and IST is employed when HSCT is not feasible due to age, lack of a histocompatible sibling, co-morbidities, or by patient choice.

\section{Keywords}

aplastic anemia; anti-thymocyte globulin; bone marrow failure; stem cell transplantation; cyclosporine; pancytopenia

\section{Introduction}

In its severe form, aplastic anemia (AA) is a life-threatening bone marrow failure disorder which, if untreated, is associated with very high mortality. Hematopoietic stem cell transplantation (HSCT) offers an opportunity for cure, but most patients are not suitable candidates for this procedure due to advanced age, comorbidities, or lack of a histocompatible donor. For these patients, comparable long term survival is attainable with immunosuppressive treatment (IST) with anti-thymocyte globulin (ATG) and cyclosporine (CsA). Although several etiopathogenic triggers have been proposed in AA, the majority of cases are idiopathic, with a small percentage of cases occurring after an episode of seronegative hepatitis. 


\section{Epidemiology and Etiology}

Acquired AA is a rare disease; almost half of cases occur during the first three decades of life. The incidence in Western countries is two cases per million per year and about 2-3-fold higher in Asia [1-3]. Benzene and pesticides, while epidemiologically associated, account for a small etiologic fraction. In rural Thailand, associated exposures to non-bottled water, as well as to certain animals, to animal fertilizer, and also to pesticides suggest an infectious etiology [2]. The rarity of acquired AA most probably is accounted for by a combination of infrequent exposure events, a diversity of host genetic predisposing factors, and individual differences in the immune response.

During the last century, AA was attributed to an idiosyncratic reaction to drug or chemical exposure. The association of medical drug use to AA is of great importance, as it is devastating to patients and physicians and presents serious legal consequences and problems in pharmaceutical drug development [4]. However, the study of idiosyncratic drug reactions, by definition extremely rare, is difficult and the only clear predisposition to abnormal drug metabolism underlying susceptibility is one study of a single individual exposed to carbamazepine published over 20 years ago [5]. Overrepresentation of drug metabolizing glutathione-S-transferase gene deletions have been observed in some series [6,7] but no reasonable mechanism has been developed for chloramphenicol.

Pregnancy and eosinophilic fasciitis are linked to AA. Five to ten percent of cases of AA follow an episode of seronegative hepatitis [8], but despite intensive efforts, an infectious agent has not been identified.

\section{Pathophysiology}

In most cases, AA behaves as an immune-mediated disease. An immune response dominated by oligoclonal expanded cytotoxic T-cells targets hematopoietic stem and progenitor cells, inducing their death via apoptosis and hematopoietic failure.

\section{T-cell-mediated destruction of the bone marrow}

Recovery of autologous hematopoiesis in patients who failed to engraft after stem cell transplant and responsiveness to immunosuppressive therapies are the major clinical evidences supporting an immune pathophysiology underlying acquired AA. Although a nonimmune pathophysiology has been inferred from a failure to respond to immunosuppression, refractoriness to therapy is also consistent with very severe stem cell depletion, a "spent" immune response, or immunological mechanisms resistant to current therapies.

Removal of lymphocytes from aplastic bone marrows improves colony numbers in tissue culture, and their addition to normal marrow inhibited hematopoiesis in vitro [9]. The effector cells within the lymphocyte subset are activated cytotoxic T cells bearing a Th1 profile, expressing and secreting interferon- $\gamma$ [10]. T-bet, a transcription factor that binds to the interferon- $\gamma$ promoter region and is critical for Th1 polarization, is up-regulated in Tcells of patients with AA [11]. Specific CD8+CD28- cell clones are expanded in AA peripheral blood, as manifest by skewed usage of the $\mathrm{V} \beta$ repertoire; and oligoclones recognize and induce apoptosis of autologous myeloid cells [12]. Regulatory T cells, which control and suppress auto-reactive T cells, are decreased at presentation in almost all patients with AA [13]. In a mouse model of immune-mediated marrow failure, addition of $\mathrm{T}$ regulatory cells abrogated pancytopenia induced by the infusion of lymph node cells [14]. 
Why T-cells are activated in AA is unclear. HLA-DR2 is over-represented among patients, suggesting a role for antigen recognition, and its presence is predictive of a better response to cyclosporine $[15,16]$. Polymorphisms in cytokine genes, associated with an increased immune response, also are more prevalent, such as for tumor necrosis factor-a (TNF2) promoter at -308 [17], interferon- $\gamma$ [18], and interleukin 6 genes [19]. These alterations in nucleotide sequence and in gene regulation suggest a genetic basis for aberrant $\mathrm{T}$ cell activation in bone marrow failure.

\section{Hematopoiesis}

Immune attack leads to marrow failure. The targets, mainly CD34+ cells, are very few or absent in the aplastic bone marrow, and minimal numbers of colonies derive from committed progenitors in semisolid media, all reflecting the severe reduction in hematopoietic progenitor cells that defines the disease. The reduced number and function of the marrow is secondary to cell destruction, and apoptosis is prevalent among the few remaining elements [20-22]. Microarray analysis of the remaining CD34+ cells shows a transcriptome shifted towards apoptosis, cell death, and immune regulation [23].

A minority of AA cases may share pathophysiologic basis with inherited marrow failure syndromes. One peculiar feature of white blood cells in AA is short telomeres, observed in approximately a third of cases [24,25]. Although initially blamed on excessive stem cell turnover, telomere shortening in some cases of acquired AA and in dyskeratosis congenita, a constitutional marrow failure syndrome is due to mutations in components of the telomerase complex, causing low telomerase activity, progressive telomere erosion, and a deficient proliferative capacity of hematopoietic stem cells [26-29]. Family members who share the mutation, despite normal or near normal blood counts, have hypocellular marrows, reduced CD34+ cell counts and poor hematopoietic colony formation, increased hematopoietic growth factor levels, and of course short telomeres; some affected relatives may present with pulmonary fibrosis or liver cirrhosis in isolation. A few adult AA patients also have heterozygous mutations in the Shwachman-Bodian-Diamond syndrome (SBDS) gene (Shwachman-Diamond syndrome occurs when patient carries biallelic mutations) [30].

\section{Clonal Evolution}

AA may coexist or evolve to clonal disorders, as paroxysmal nocturnal hemoglobinuria (PNH), myelodysplasia (MDS), or acute myeloid leukemia (AML). The mechanisms linking immune-mediated and pre-malignant or malignant pathophysiologies are not well elucidated in marrow failure or in other human autoimmune diseases that predispose to cancer.

\section{PNH}

About $40-50 \%$ of patients with acquired AA have expanded populations of PNH cells, easily detected by flow cytometry due to the absence of glycosylphosphatidylinositol-linked membrane proteins, the result of somatic $P I G-A$ gene mutations arising in hematopoietic stem cells [31]. Most clones are small and do not lead to clinical manifestations of hemolysis or thrombosis, but classic PNH can evolve to marrow failure (the AA/PNH syndrome) and all PNH patients show evidence of underlying hematopoietic deficiency. The global absence of large number of cell surface proteins in PNH has been hypothesized to allow escape and survival of a pre-existing mutant clone.

\section{MDS}

Aneuploidy develops in a minority of patients treated with immunosuppression over time, usually monosomy 7 and trisomy $8[32]$. AA patients who develop trisomy 8 usually respond to IST [33]. T-cell oligoclones appear to recognize the aneuploid cells and specifically WT1 
as an antigen, but target cells are not killed due to their expression of anti-apoptotic genes [34].

Monosomy 7 is the most frequent cytogenetic abnormality in evolving AA; it confers a poor prognosis: with typical associated refractory cytopenia or AML[35]. Monosomy 7 has been linked to exogenous use of G-CSF in AA [36,37] and laboratory studies suggest that aneuploid clones expand in an abnormal cytokine milieu rich in G-CSF due to the presence of a short G-CSF receptor isoform, which signals proliferation but not differentiation [38]. The presence of even small monosomy 7 clones in the bone marrow, as detected by FISH (but not by routine cytogenetics), is a poor prognostic indicator for response to IST [39].

\section{Immunosuppressive therapy}

Horse anti-thymocyte globulin (ATGAM (R); h-ATG) is the only drug approved by the Food and Drug Administration for the treatment of AA. While it is generally believed that $h-$ ATG administration leads to depletion of immune competent cells, its exact mechanism of action remains unclear [40]. H-ATG preparations contain a variety of antibodies recognizing human T-cell epitopes, many directed against activated T-cells or activation antigens $[41,42]$. Although the decline in circulating levels of lymphocytes is transient, the number of activated T -cells is decreased for more prolonged periods of time; this effect is also reflected in decreased $1 \mathrm{FN}-\gamma$ and possibly TNF production after h-ATG [10]. In contrast to ATG, CsA has a more selective inhibitory effect on T lymphocytes, suppressing early cellular response to antigenic and regulatory stimuli. By blocking expression of nuclear regulatory proteins, it leads to reduced $\mathrm{T}$ cell proliferation and activation with diminished release of cytokines such as interleukin- 2 and interferon- $\gamma$. The combination of h-ATG and CsA is current standard therapy in severe AA (SAA) [43,44]. The benefits (and limitations) of this regimen as initial therapy have been quantitated in systematic studies in the US, Japan and Europe: overall response is achieved in about $2 / 3$ of patients; the cumulative incidence of relapse among responders is approximately $20-30 \%$ and clonal evolution occurs in about $10-15 \%$ of cases [45-48]. The majority of responses to IST are not complete, notwithstanding, hematologic response almost always equates to cessation of transfusion, and multiple studies have shown a strong correlation between hematologic response and long term survival $[45,49]$. Pediatric population studies in general report a higher response rate of about $70-80 \%$ with long term survival of $80-90 \%$; relapse and clonal evolution occur at rates that are comparable to what is observed in patients of all ages $[47,50,51]$.

Both refractory and relapsed patients are frequently treated with further courses of ATG. In these settings, rabbit ATG (r-ATG) + CsA has been frequently used. R-ATG is similar to hATG except that gamma immune globulin is obtained by immunization of rabbits with human thymocytes. Clinically, r-ATG appears to be more immunosuppressive as a more prolonged lymphopenia is observed with this agent compared to h-ATG [52]. This enhanced lymphocytotoxicity of r-ATG may be explained by higher affinity IgG subtype to human lymphocytes, less batch-to-batch variability, longer half-life, and more efficient lymphocyte depletion [53]. In addition, $\mathrm{r}$-ATG may promote immune regulation as suggested by an in vitro assay where $\mathrm{CD} 4+\mathrm{CD} 25$ - were converted to $\mathrm{CD} 4+\mathrm{CD} 25+$ regulatory $\mathrm{T}$ cells in the presence of r-ATG but not h-ATG [54]. For the $1 / 3$ of patients who are refractory to h-ATG/ CsA, repeated courses of immunosuppression have yielded response rates varying from $30-$ 70\% [55-57]. For relapsed patients, re-introduction of CsA commonly result in improvement in blood counts, however, CsA-dependence is frequent and the dose of CsA usually is tapered slowly with hematologic monitoring [45]. Re-treatment with ATG/CsA in relapsed AA has resulted in response rates of 50-60\% [56-58]. In our experience, relapse 
does not correlate to a poor prognosis, as patients often respond to re-introduction of CsA and/or re-treatment with ATG.

In contrast, patients refractory to initial h-ATG historically have had a dire outcome, with long term survival rates in the 1990s of 20-30\% [45]. However, we have noted a striking improvement in survival among non-responders to initial h-ATG treated at our institution in recent years [59]. Retrospective analysis has shown that the decrease in deaths in refractory patients is most likely due to more successful salvage therapies (repeat IST and HSCT) as well as better supportive care, mainly the introduction of better antifungal drugs.

Despite better understanding of the pathogenesis of SAA, methods to predict response to IST are lacking. Proposed criteria to date have been complex or relied on non-standardized tests. A recently completed retrospective analysis of over 300 patients treated with h-ATG/ CsA at our institution showed that baseline absolute reticulocyte count (ARC) and absolute lymphocyte count (ALC) combined served as a good predictor of response to IST [60]: patients with an ARC $\geq 25,000$ and ALC $\geq 1,000 / \mathrm{uL}$ at baseline had an $80 \%$ response rate compared to $40 \%$ with those with an ARC $<25,000$ and ALC $<1,000 / u L$. Age less than 18 years also correlated to improved response (about 75\%). Since the addition of CsA to hATG, efforts to improve beyond h-ATG/CsA have been frustrating. The addition of a third immunosuppressive drug to the h-ATG + CsA standard regimen (mycophenolate mofetil, sirolimus, androgens, corticosteroids) have not resulted in better response rates or decreased relapse rates and clonal evolution [47,61-63]; and more potent lymphocytotoxic agents have been associated with unacceptable toxicities [64]. The role of G-CSF in adjunction to ATG + CsA remains controversial. A recent reported Japanese randomized study suggested that the addition of G-CSF might reduce the incidence of relapse [65], but this results was not observed in other studies of similar design [66]. In addition, a higher incidence of evolution has been reported in AA patients who receive G-CSF [37]. A large multicenter randomized European trial is under way which compares ATG and CsA with or without G-CSF which will more definitively address the benefits and possible pitfalls of cytokine addition in SAA.

In moderate AA, the clinical course is variable: some patients progress to severe disease, others remain stable and may not require intervention; regular transfusions may not be required [67]. Very few clinical trials have specifically addressed moderate disease. Immunosuppression can reverse moderate pancytopenia and alleviate transfusion requirements; ATG and cyclosporine are more effective in combination [68]. Daclizumab, a humanized monoclonal antibody to the interleukin- 2 receptor, improved blood counts and relieved transfusion requirements in 6 of 16 evaluable patients; the outpatient regimen had little toxicity [69].

\section{Allogeneic Hematopoietic Stem Cell Transplantation HLA-matched sibling donor transplant}

Allogeneic bone marrow transplantation from a histocompatible matched sibling is curative therapy in the majority of SAA patients who undergo this procedure . The most recent cohort reported to the IBMTR showed 77\% 5-year survival [70], and in children and patients who were minimally transfused, survival of $80-90 \%$ may be routinely achieved [71]. Acute grade II-IV graft-versus-host-disease (GVHD) occurs in about 20-30\% of patients and chronic GVHD in 30-40\% [71,72]. Chronic GVHD has been a major cause of morbidity and mortality in patients who survived more than 2 years post graft, with the necessity of long term immunosuppressive therapy common [72]. Graft rejection, a historic problem in the application of transplant to SAA is now infrequent, likely a benefit of less immunogenic blood products (leukocyte-depleted erythrocytes, for example) from fewer donors (platelets collected by cytoapheresis) [73,74]. Also, better radiation-free conditioning regimens have 
improved the tolerability of HSCT and allowed for engraftment in heavily transfused (and in some cases alloimmunized) patients who were refractory to IST $[75,76]$. The frequently employed conditioning regimen of cyclophosphamide + ATG was compared to cyclophosphamide in a prospective randomized study [77]: no differences in engraftment, GVHD, and survival rates were observed between the two groups, suggesting that the better outcome with HSCT over time relates to advances in supportive care. The main source of stem cells up to 2000 has been bone marrow cells; in recent years, G-CSF peripheral blood (PB) mobilized CD34+ have become more widely used. In a retrospective analysis, the use of PB progenitor cell graft has been correlated to a worse outcome and more chronic GVHD in younger patients (less than 20) compared to those who receive a bone marrow graft in HLA-matched sibling donor transplants [78]. This difference was not observed in older patients.

\section{Matched unrelated donor transplant}

A matched sibling donor is available in only $20-30 \%$ of cases. As the outcome in aplastic patients who have failed a single round of ATG has been poor, alternative sources of hematopoietic stem cells have been sought, usually from now very large donor registries. Data from large retrospective studies suggest that the outcome for an unrelated donor HSCT remains less favorable compared to a matched-related transplant, due to more GVHD, a mortality rate that is about twice that observed in matched sibling transplants, and long term survival of about $50 \%$ [70,79-81]. Older patients with poor performance status have the worst outcome and better results are obtained in children than for adults. Progress in donor selection through high-resolution HLA typing technology has likely contributed to decreased graft rejection and better survival [82] and recently reported outcomes for MUD rival those for an HLA-matched sibling transplant in children and young adults [83,84].

The optimal conditioning regimen for a MUD HSCT remains uncertain; in contrast to allogeneic sibling transplants, transplants from unrelated donors still require low dose irradiation (200 cGy) to ensure engraftment, with attendant long-term complications [85,86]. In general, prospective trials have enrolled fewer patients but have better results, albeit with short periods of post-transplant observation [71]. A multicenter prospective study compared the outcomes of a second course of IST to a MUD HSCT in children who failed initial course of IST: among the 60 initial ATG failures, 21 underwent a MUD HSCT and 31 received a second course of IST. Those who underwent a MUD HSCT had a higher failure free survival (defined as survival with response) compared to those who underwent a second course of IST, although no difference in overall survival was observed between the 2 groups [87].

\section{Conclusion}

In recent years, further evidence has accumulated to strengthen the hypothesis that bone marrow failure in AA results from immunologic destruction of hematopoietic stem and progenitor cells. In a minority of patients with shortened telomeres, a qualitative disorder may accompany the numerical diminution of CD34+ cells in the bone marrow. Current research is aimed at investigating the mechanisms that lead to $\mathrm{T}$ cell activation and, whether it is antigen driven or a result of immunological disarray. The clinical implication of telomere shortening in AA is being investigated for prognostic significance. Most patients with AA are now expected to survive regardless of the treatment modality employed. Advances in supportive care and better salvage therapies have produced significantly increased survival among initial non-responders to ATG+ CsA; the decrease in allosensitization (through routine leucodepletion of blood products) and better donor selection (through high molecular HLA-typing) have improved the outcomes of both related and unrelated HSCT; long term survival in pediatric patients who respond to IST is excellent and 
ATG based regimen should be offered as initial therapy to those who lack a matched sibling donor. Our practice has been to consider an alternative donor HSCT in suitable pediatric patients who have failed an initial course of ATG + CSA or in adults who have failed two courses of IST. Refractory patients who are not suitable candidates for alternative donor HSCT can be supported through a combination of transfusions, androgens and/or administration of hematopoietic growth factors. In chronically transfused patients, iron overload can now be managed with more convenient oral agents (deferasirox, Exjade ${ }^{\text {) }}$ ) and, the prospect of approval of newer oral thrombopoietic drugs is likely to ease platelet transfusion requirements especially in AA patients who are refractory to IST.

\section{References}

1. Kaufman, DW.; Kelly, JP.; Levy, M.; Shapiro, S. The Drug Etiology of Agranulocytosis and Aplastic Anemia. Oxford; New York: 1991.

*2. Issaragrisil S, Kaufman D, Anderson T, Chansung K, Leaverton P, Shapiro S, Young NS, The Aplastic Anemia Study G. The epidemiology of aplastic anemia in Thailand. Blood. 2006; 107:1299-1307. [PubMed: 16254144] This large epidemiologic study enrolled more than 500 patients and 2,000 case controls; an accurate incidence rate was obtained, and there were environmental associations with the disease that were familiar (chemicals and drugs) and others that were unexpected (water source, animal exposure).

3. Hamerschlak N, Maluf E, Pasquini R, Eluf-Neto J, Moreira FR, Cavalcanti AB, Okano ÍR, Falcão RP, Pita MT, Loggetto SR, et al. Incidence of aplastic anemia and agranulocytosis in Latin America: the LATIN study. Sao Paulo Medical Journal. 2005; 123:101-104. [PubMed: 16021270]

4. Young, NS.; Young, NS.; Alter, BP. Drugs and chemicals. In: Saunders, WB., editor. Aplastic Anemia, Acquired and Inherited. 1994. p. 100-132.

5. Gerson WT, Fine DG, Spielberg SP, Sensenbrenner LL. Anticonvulsant-induced aplastic anemia: increased susceptibility to toxic drug metabolites in vitro. Blood. 1983; 61:889-893. [PubMed: 6831050]

6. Sutton JF, Stacey M, Kearsey SE, Reig TS, Young NS, Liu JM. Increased risk for aplastic anemia and myelodysplastic syndrome in individuals lacking GSTT1 gene. Pediatric Blood Cancer. 2004; 42:122-126. [PubMed: 14752874]

7. Dufour C, Syahn J, Bacigalupo A, Longoni D, Varotto S, Iori AP, Bagnasco F, Locasciulli A, Menna G, Ramenghi U, et al. Genetic polymorphisms of CYP3A4, GSTT1, GSTM1, GSTP1 and NQO1 and the risk of acquired idiopathic aplastic anemia in Caucasian patients. Haematologica. 2005; 90:1027-1031. [PubMed: 16079101]

8. Lu J, Basu A, Melenhorst J, Young NS, Brown KE. Analysis of T-cell repertoire in hepatitisassociated aplastic anemia. Blood. 2004; 103:4588-4593. [PubMed: 14988156]

9. Young NS. Hematopoietic cell destruction by immune mechanisms in aquired aplastic anemia. Seminars in Hematology. 2000; 37:3-14. [PubMed: 10676907]

10. Sloand EM, Kim S, Maciejewski JP, Tisdale J, Follmann D, Young NS. Intracellular interferon- y in circulating and marrow T cells detected by flow cytometry and the response to imunosuppressive therapy in patients with aplastic anemia. Blood. 2002; 100:1185-1191. [PubMed: 12149196]

*11. Solomou EE, Keyvanfar K, Young NS. T-bet, a Th1 transcription factor, is up-regulated in T cells from patients with aplastic anemia. Blood. 2006; 107:3983-3991. [PubMed: 16434488] The T cell polarizing transcription factor T-bet was increased in T cells from most patients with aplastic anemia.

12. Risitano AM, Maciejewski JP, Green S, Plasilova M, Zeng W, Young NS. In-vivo dominant immune responses in aplastic anaemia: molecular tracking of putatively pathogenetic T-cell clones by TCR [beta]-CDR3 sequencing. The Lancet. 2004; 364:355-364.

**13. Solomou EE, Rezvani K, Mielke S, Malide D, Keyvanfar K, Visconte V, Kajigaya S, Barrett AJ, Young NS. Deficient CD4+ CD25+ FOXP3+ T regulatory cells in acquired aplastic anemia. Blood. 2007; 110:1603-1606. [PubMed: 17463169] Regulatory T cells were decreased at presentation in almost all patients; a regulatory $\mathrm{T}$ cell defect 16 was implicated in autoimmune 
marrow failure as had been suggested by animal studies and in a few other human autoimmune diseases.

*14. Chen J, Ellison FM, Eckhaus MA, Smith AL, Keyvanfar K, Calado RT, Young NS. Minor Antigen H60-Mediated Aplastic Anemia Is Ameliorated by Immunosuppression and the Infusion of Regulatory T Cells. J Immunol. 2007; 178:4159-4168. [PubMed: 17371972] In an immunemediated murine model for AA, a single minor histocompatibility mismatch triggered an immune response leading to massive bone marrow destruction. Immunosuppressive drug treatment or enhancement of regulatory $\mathrm{T}$ cell function protected animals from the development of bone marrow failure.

15. Nakao S, Takamatsu H, Chuhjo T, Ueda M, Shiobara S, Matsuda T, Kaneshige T, Mizoguchi H. Identification of a specific HLA class II haplotype strongly associated with susceptibility to cyclosporine-dependent aplastic anemia. Blood. 1994; 84:4257-4261. [PubMed: 7994040]

16. Maciejewski JP, Follmann D, Rivera CE, Brown KE, Simonis T, Young NS. Increased frequency of HLA-DR2 in patients with paroxysmal nocturnal hemoglobinuria and PNH/aplastic anemia syndrome. Blood. 2001; 98:3513-3519. [PubMed: 11739151]

17. Demeter J, Messer G, Schrezenmeier H. Clinical relevance of the TNF-alpha promoter/enhancer polymorphism in patients with aplastic anemia. Ann Hematol. 2002; 81:566-569. [PubMed: 12424537]

18. Dufour C, Capasso M, Svahn J, Marrone A, Haupt R, Bacigalupo A, Giordani L, Longoni D, Pillon M, Pistorio A, et al. Homozygosis for (12) CA repeats in the first intron of the human IFNgamma gene is significantly associated with the risk of aplastic anaemia in Caucasian population. Br J Haematol. 2004; 126:682-685. [PubMed: 15327519]

19. Gidvani V, Ramkissoon S, Wong E, Sloand EM, Young NS. Cytokine gene polymorphisms in acquired bone marrow failure. American Journal of Hematology. 2007

20. Philpott NJ, Scopes J, Marsh JCW, Gordon-Smith EC, Gibson FM. Increased apoptosis in aplastic anemia bone marrow progenitor cells: possible pathophysiologic significance. Experimental Hematology. 1995; 23:1642-1648. [PubMed: 8542959]

21. Callera F, Falcao RP. Increased apoptotic cells in bone marrow biopsies from patients with aplastic anaemia. British Journal of Haematology. 1997; 98:18-20. [PubMed: 9233557]

22. Maciejewski JP, Selleri C, Sato T, Anderson S, Young NS. Increased expression of Fas antigen on bone marrow CD34+ cells of patients with aplastic anemia. Britis Journal of Haematology. 1995; 91:245-252.

23. Chen G, Zeng W, Miyazato A, Billings E, Maciejewski JP, Kajigaya S, Sloand EM, Young NS. Distinctive gene expression profiles of CD34 cells from patients with myelodysplastic syndrome characterized by specific chromosomal abnormalities. Blood. 2004; 104:4210-4218. [PubMed: 15315976]

24. Ball SE, Gibson FM, Rizzo S, Tooze JA, Marsh JCW, Gordon-Smith EC. Progressive telomere shortening in aplastic anemia. Blood. 1998; 91:3582-3592. [PubMed: 9572992]

25. Brummendorf TH, Maciejewski JP, Young NS, Lansdorp PL. Telomere length in leukocyte subpopulations of patients with aplastic anemia. Blood. 2001; 97:895-900. [PubMed: 11159514]

26. Fogarty PF, Yamaguchi H, Wiestner A, Baerlocher GM, Sloand EM, Zeng W, Read EJ, Lansdorp PM, Young NS. Late presentation of dyskeratosis congenita as apparently acquired aplastic anaemia due to mutations in telomerase RNA. Lancet. 2003; 362:1628-1630. [PubMed: 14630445]

27. Yamaguchi H, Calado RT, Ly H, Baerlocher GM, Kajigaya S, Chanock SJ, Lansdorp PM, Young NS. Mutations in TERT, the gene for telomerase reverse transcriptase, in aplastic anemia. N Eng J Med. 2005; 352:1413-1424.

28. Knight SW, Heiss NS, Vulliamy TJ, Greschner S, Stavrides G, Pai GS, Lestringant G, Varma N, Mason PJ, Dokal I, et al. X-linked dyskeratosis congenita is predominantly caused by missense mutations in the DKC1 gene. American Journal of Human Genetics. 1999; 65:50-58. [PubMed: 10364516]

29. Vulliamy T, Marrone A, Goldman F, Dearlove A, Bessler M, Mason P, Dokal I. The RNA component of telomerase is mutated in autosomal dominant dyskeratosis congenita. Nature. 2001; 413:432-435. [PubMed: 11574891] 
*30. Calado RT, Graf SA, Wilkerson KL, Kajigaya S, Ancliff PJ, Dror Y, Chanock SJ, Lansdorp PM, Young NS. Mutations in the SBDS gene in acquired aplastic anemia. Blood. 2007; 110:11411146. [PubMed: 17478638] Heterozygosity for $S B D S$ mutations previously described in Shwachman-Diamond syndrome, were identified in young patients with idiopathic acquired AA.

31. Young NS. Paroxysmal nocturnal hemoglobinuria: current issues in pathophysiology and treatment. Curr Hematol Rep. 2005; 4:103-109. [PubMed: 15720958]

32. Maciejewski JP, Selleri C. Evolution of clonal cytogenetic abnormalities in aplastic anemia. Leukemia and Lymphoma. 2004; 45:433-440. [PubMed: 15160903]

33. Sloand EM, Mainwaring L, Fuhrer M, Ramkissoon S, Risitano A, Keyvanfar K, Lu J, Basu A, Barrett AJ, Young NS. Preferential suppression of trisomy 8 compared with normal hematopoietic cell growth by autologous lymphocytes in patients with trisomy 8 myelodysplastic syndrome. Blood. 2005; 106:841-851. [PubMed: 15827127]

**34. Sloand EM, Pfannes L, Chen G, Shah S, Solomou EE, Barrett J, Young NS. CD34 cells from patients with trisomy 8 myelodysplastic syndrome (MDS) express early apoptotic markers but avoid programmed cell death by up-regulation of antiapoptotic proteins. Blood. 2007; 109:2399 2405. [PubMed: 17090657] Resistance to apoptosis underlies clonal expansion of CD34 cells from patients with trisomy 8 myelodysplastic syndrome.

35. Maciejewski JP, Risitano AM, Sloand EM, Nunez O, Young NS. Distinct clinical outcomes for cytogenetic abnormalities evolving from aplastic anemia. Blood. 2002; 99:3129-3135. [PubMed: 11964274]

36. Kojima S, Ohara A, Tsuchida M, Kudoh T, Hanada R, Okimoto Y, Kaneko T, Takano T, Ikuta K, Tsukimoto I. Risk factors for evolution of acquired aplastic anemia into myelodysplastic syndrome and acute myeloid leukemia after immunosuppressive therapy in children. Blood. 2002; 100:786790. [PubMed: 12130487]

*37. Socie G, Mary J-Y, Schrezenmeier H, Marsh J, Bacigalupo A, Locasciulli A, Fuehrer M, Bekassy A, Tichelli A, Passweg J. Granulocyte-stimulating factor and severe aplastic anemia: a survey by the European Group for Blood and Marrow Transplantation (EBMT). Blood. 2007; 109:27942796. [PubMed: 17110459] In this retrospective study, an increased incidence of evolution to myelodysplasia and leukemia was observed in AA patients who received initial immunosuppressive therapy with G-CSF compared to those who did not receive G-CSF with initial immunosuppression.

**38. Sloand, EM.; Yong, ASM.; Ramkissoon, S.; Solomou, E.; Bruno, TC.; Kim, S.; Fuhrer, M.; Kajigaya, S.; Barrett, AJ.; Young, NS. Granulocyte colony-stimulating factor preferentially stimulates proliferation of monosomy 7 cells bearing the isoform IV receptor. Proceedings of the National Academy of Sciences; 2006. p. 14483-14488.Monosomy 7 cells expressed truncated GCSF receptor isoform that stimulates proliferation but not differentiation, favoring monosomy 7 cell expansion in the presence of pharmacological doses of G-CSF.

39. Sloand, EM.; Scheinberg, P.; Fenlon, E.; Blancato, J.; Pfannes, L.; Young, NS. Monosomy 7 Detected by FISH at Disease Presentation Is a Marker for Non-Response to Immunosuppression. ASH Annual Meeting Abstracts; 2007. p. 506a

40. Young, NS.; Alter, BP. Aplastic Anemia, Acquired and Inherited. Saunders; Philadelphia: 1994.

41. Bourdage JS, Hamlin DM. Comparative polyclonal antithymocyte globulin and antilymphocyte/ antilymphoblast globulin anti-CD antigen analysis by flow cytometry. Transplantation. 1995; 59:1194-1200. [PubMed: 7732566]

42. Raefsky EL, Gascon P, Gratwohl A, Speck B, Young NS. Biological and immunological characterization of ATG and ALG. Blood. 1986; 68:712-719. [PubMed: 3091115]

43. Frickhofen N, Kaltwasser JP, Schrezenmeier H, Raghavachar A, Vogt HG, Herrmann F, Freund M, Meusers P, Salama A, Heimpel H. Treatment of aplastic anemia with antilymphocyte globulin and methylprednisolone with or without cyclosporine. The German Aplastic Anemia Study Group. New England Journal of Medicine. 1991; 324:1297-1304. [PubMed: 2017225]

44. Frickhofen N, Rosenfeld SJ. Immunosuppressive treatment of aplastic anemia with antithymocyte globuilin and cyclosporine. Seminars in Hematology. 2000; 37:56-68. [PubMed: 10676911]

45. Rosenfeld S, Follman D, Nuaez O, Young NS. Antithymocyte globulin and cyclosporine for severe aplastic anemia. Association between hematologic response and long-term outcome. Journal of the American Medical Association. 2003; 289:1130-1135. [PubMed: 12622583] 
46. Bacigalupo A, Bruno B, Saracco P, Di Bona E, Locasciulli A, Locatelli F, Gabbas A, Dufour C, Arcese W, Testi G, et al. Antilymphocyte globuilin, cyclosporine, prednisolone, and granulocyte colony-stimulating factor for severe aplastic anemia: an update of the GITMO/EBMT study on 100 patients. European Group for Blood and Marrow Transplantation (EBMT) Working Party on Severe Aplastic Anemia and the Gruppo Italiano Trapianti di Midolio Osseo (GITMO). Blood. 2000; 95:1931-1934. [PubMed: 10706857]

47. Kojima S, Hibi S, Kosaka Y, Yamamoto M, Tsuchida M, Mugishima H, Sugita K, Yabe H, Ohara A, Tsukimoto I. Immunosuppressive therapy using antithymocyte globulin, cyclosporine, and danazol with or without human granulocyte colony-stimulating factor in children with acquired aplastic anemia. Blood. 2000; 96:2049-2054. [PubMed: 10979946]

48. Frickhofen N, Heimpel H, Kaltwasser JP, Schrezenmaier H. Antithymocyte globulin with or without cyclosporin A: 11-year follow-up of a randomized trial comparing treatments of aplastic anemia. Blood. 2003; 101:1236-1242. [PubMed: 12393680]

49. Fuhrer M, Rampf U, Baumann I, Faldum A, Niemeyer C, Janka-Schaub G, Friedrich W, Ebell W, Borkhardt A, Bender-Goetze C, et al. Immunosuppressive therapy for aplastic anemia in children: a more severe disease predicts better survival. Blood. 2005; 106:2102-2104. [PubMed: 15933058]

50. Fuhrer M, Burdach S, Ebell W, Gadner H, Haas R, Harbott J, Janka-Schaub G, Klingebiel T, Kremens B, Niemeyer C, et al. Relapse and clonal disease in children with aplastic anemia (AA) after immunosuppressive therapy (IST): the SAA 94 experience. Klinische Padiatrie. 1998; 210:173-179. [PubMed: 9743949]

51. Scheinberg, P.; Wu, CO.; Nunez, O.; Young, NS. Long Term Outcome of Pediatric Patients with Severe Aplastic Anemia Treated with Anti-Thymocyte Globulin and Cyclosporine. ASH Annual Meeting Abstracts; 2007. p. 505a

52. Scheinberg P, Fischer SH, Li L, Nunez O, Wu CO, Young NS, Sloand EM, Cohen JI, Barrett AJ. Distinct EBV and CMV reactivation patterns following antibody-based immunosuppressive regimens in patients with severe aplastic anemia. Blood. 2007; 109:3219-3224. [PubMed: 17148582]

53. Thomas FT, Griesedieck C, Thomas J. Differential effects of horse ATG and rabbit ATG on T cell and $\mathrm{T}$ cell subset levels measured by monoclonal antibodies. Transplantation Proceedings. 1984; 16:1561-1563. [PubMed: 6239426]

54. Feng X, Solomou EE, Keyvanfar K, Herndon T, Chen J, Kajigaya S, Young NS. Rabbit ATG but Not Horse ATG Promotes Expansion of Functional CD4+CD25highFoxP3 Regulatory T Cells In Vitro. ASH Annual Meeting Abstracts. 2007; 110:684a.

55. Di Bona E, Rodeghiero F, Bruno B, Gabbas A, Foa P, Locasciulli A, Rosanelli C, Camba L, Saracco P, Lippi A, et al. Rabbit antithymocyte globulin (r-ATG) plus cyclosporine and granulocyte colony stimulating factor is an effective treatment for aplastic anaemia patients unresponsive to a first course of intensive immunosuppressive therapy. Gruppo Italiano Trapianto di Midollo Osseo (GITMO). Br J Haematol. 1999; 107:330-334. [PubMed: 10583220]

56. Tichelli A, Passweg J, Nissen C, Bargetzi M, Hoffmann T, Wogner-Filipowicz A, Signer E, Speck B, Gratwohl A. Repeated treatment with horse antilymphocyte globulin for severe aplastic anaemia. Br J Haematol. 1998; 100:393-400. [PubMed: 9488634]

*57. Scheinberg P, Nunez O, Young NS. Retreatment with rabbit anti-thymocyte globulin and ciclosporin for patients with relapsed or refractory severe aplastic anaemia. Br J Haematol. 2006; 133:622-627. [PubMed: 16704436] In horse ATG refractory patients, 1/3 of patients are salvaged with repeat immunosuppressive therapy with rabbit ATG; and in patients with relapsed AA, 2/3 of patients respond to retreatment with rabbit ATG.

58. Schrezenmeier H, Marin P, Raghavachar A, McCann S, Hows J, Gluckman E, Nissen C, Van't Veer-Korthof ET, Ljungman P, Hinterberger W, et al. Relapse of aplastic anaemia after immunosuppressive treatment: a report from the European Bone Marrow Transplantation Group SAA Working Party. British Journal of Haematology. 1993; 85:371-377. [PubMed: 8280610]

59. Scheinberg P, Wu CO, Nunez O, Young NS. Marked Improvement in Short-and Long-Term Survival in Severe Aplastic Anemia Patients Treated with Immunosuppression in the Past 18 Years. ASH Annual Meeting Abstracts. 2007; 110:506a. 
60. Scheinberg P, Wu CO, Nunez O, Young NS. Predicting Response and Survival for Severe Aplastic Anemia Patients Treated with Immunosuppression. ASH Annual Meeting Abstracts. 2007; 110:504a.

*61. Scheinberg P, Nunez O, Wu C, Young NS. Treatment of severe aplastic anaemia with combined immunosuppression: anti-thymocyte globulin, ciclosporin and mycophenolate mofetil. Br J Haematol. 2006; 133:606-611. [PubMed: 16704434] In this study of over 100 AA patients, the addition of mycophenolate mofetil to standard horse ATG + cyclosporine did not improve the rates of response or relapse.

62. Jeng MR, Naidu PE, Rieman MD, Rodriguez-Galindo C, Nottage KA, Thornton DT, Li CS, Wiang WC. Granulocyte-macrophage colony stimulating factor and immunosuppression in the treatment of pediatric acquired severe aplastic anemia. Pediatr Blood Cancer. 2005; 45:170-175. [PubMed: 15593082]

63. Gluckman E, Rokicka-Milewska R, Hann I, Nikiforakis E, Tavakoli F, Cohen-Scali S, Bacigalupo A. Results and follow-up of a phase III randomized study of recombinant human-granulocyte stimulating factor as support for immunosuppressive therapy in patients with severe aplastic anaemia. Brit J Haem. 2002; 119:1075-1082.

64. Tisdale JF, Dunn DE, Geller NL, Plante M, Nunez O, Dunbar CE, Barrett AJ, Walsh TJ, Rosenfeld SJ, Young NS. High-dose cyclophosphamide in severe aplastic anemia: a randomized trial. Lancet. 2000; 356:1554-1559. [PubMed: 11075769]

*65. Teramura M, Kimura A, Iwase S, Yonemura Y, Nakao S, Urabe A, Omine M, Mizoguchi H. Treatment of severe aplastic anemia with antithymocyte globulin and cyclosporin A with or without G-CSF in adults: a multicenter randomized study in Japan. Blood. 2007; 110:1756-1761. [PubMed: 17526862] In this prospective randomized study comparing horse ATG + cyclosporine with or without G-CSF, no differences in the incidence of infections, clonal evolution or survival were observed between the 2 groups; however, a higher response rate and a lower relapse rate were observed in the G-CSF treated patients.

66. Kojima S, Horibe K, Inaba J, Yoshimi A, Takahashi Y, Kudo K, Kato K, Matsuyama T. Long-term outcome of acquired aplastic anaemia in children: comparison between immunosuppressive therapy and bone marrow transplantation. British Journal of Haematology. 2000; 111:321-328. [PubMed: 11091219]

67. Howard SC, Naidu PE, Hu XJ, Jeng MR, Rodriguez-Galindo C, Rieman MD, Wang WC. Natural history of moderate aplastic anemia in children. Pediatr Blood Cancer. 2004; 43:545-551. [PubMed: 15382271]

68. Marsh J, Schrezenmeier H, Marin P, Ilhan O, Ljungman P, McCann S, Socie G, Tichelli A, Passweg J, Hows J, et al. Prospective randomized multicenter study comparing cyclosporin alone versus the combination of antithymocyte globulin and cyclosporin for treatment of patients with nonsevere aplastic anemia: A report from the European Blood and Marrow Transplant (EBMT) Severe Aplastic Anemia Working Party. Blood. 1999; 93:2191-2195. [PubMed: 10090926]

69. Maciejewski JP, Sloand EM, Nunez O, Boss C, Young NS. Recombinant humanized anti-IL-2 receptor antibody (Daclizumab) produces responses in patients with moderate aplastic anemia. Blood. 2003; 102:3584-3586. [PubMed: 12881307]

70. Horowitz MM. Current status of allogeneic bone marrow transplantation in acquired aplastic anemia. Seminars in Hematology. 2000; 37:30-42. [PubMed: 10676909]

*71. Young NS, Calado RT, Scheinberg P. Current concepts in the pathophysiology and treatment of aplastic anemia. Blood. 2006; 108:2509-2519. [PubMed: 16778145] This is a comprehensive review of the pathophysiology and treatment of AA.

72. Deeg HJ, Leisenring W, Storb R, Nims J, Flowers MED, Witherspoon RP, Sanders J, Sullivan KM. Long-term outcome after marrow transplantation for severe aplastic anemia. Blood. 1998; 91:3637-3645. [PubMed: 9572999]

73. Stroncek DF, Rebulla P. Platelet transfusions. Lancet. 2007; 370:427-438. [PubMed: 17679020]

74. Klein HG, Spahn DR, Carson JL. Red blood cell transfusion in clinical practice. Lancet. 2007; 370:415-426. [PubMed: 17679019]

75. Gomez-Almaguer D, Vela-Ojeda J, Jaime-Perez JC, Gutierrez-Aguirre CH, Cantu-Rodriguez OG, Sobrevilla-Calvo P, Rivas-Vera S, Gomez-Rangel JD, Ruiz-Arguelles GJ. Allografting in patients with severe, refractory aplastic anemia using peripheral blood stem cells and a fludarabine-based 
conditioning regimen: The Mexican experience. Am J Hematol. 2006; 81:157-161. [PubMed: 16493614]

*76. Srinivasan R, Takahashi Y, McCoy JP, Espinoza-Delgado I, Dorrance C, Igarashi T, Lundqvist A, Barrett AJ, Young NS, Geller N, et al. Overcoming graft rejection in heavily transfused and allo-immunised patients with bone marrow failure syndromes using fludarabine-based haematopoietic cell transplantation. British Journal of Haematology. 2006; 133:305-314. [PubMed: 16643433] Successful engraftment in heavily transfused (and sometimes alloimmunized) AA patients was achieved using a reduced-intensity conditioning with fludarabine, cyclophosphamide, and ATG.

**77. Champlin RE, Perez WS, Passweg JR, Klein JP, Camitta BM, Gluckman E, Bredeson CN, Eapen M, Horowitz MM. Bone marrow transplantation for severe aplastic anemia: a randomized controlled study of conditioning regimens. Blood. 2007; 109:4582-4585. [PubMed: 17272503] In this prospective randomized study, conditioning with cyclophosphamide + ATG was not shown to be superior to cyclophosphamide alone in AA patients

**78. Schrezenmeier H, Passweg JR, Marsh JCW, Bacigalupo A, Bredeson CN, Bullorsky E, Camitta BM, Champlin RE, Gale RP, Fuhrer M, et al. Worse outcome and more chronic GVHD with peripheral blood progenitor cells than bone marrow in HLA-matched sibling donor transplants for young patients with severe acquired aplastic anemia. Blood. 2007; 110:1397-1400. 21. [PubMed: 17475907] In this retrospective study, AA patients younger than 20 years of age had a higher incidence of chronic GVHD with peripheral blood progenitor mobilization compared to those who received a bone marrow graft.

**79. Passweg JR, Perez WS, Eapen M, Camitta BM, Gluckman E, Hinterberger W, Hows JM, Marsh JCW, Pasquini R, Schrezenmeier H, et al. Bone marrow transplants from mismatched related and unrelated donors for severe aplastic anemia. Bone Marrow Transplant. 2006; 37:641-649. [PubMed: 16489361] This is a large retrospective analysis of the long term outcome of AA patients who underwent an unrelated stem cell transplantion between 1988 and 1998 and reported to the Center for International Blood and Marrow Transplant Research (CIBMTR). Overall, 5year survival was about $50 \%$, with poor performance score and older age adversely affecting outcomes after transplantation.

80. Kojima S, Matsuyama T, Kato S, Kigasawa H, Kobayashi R, Kikuta A, Sakamaki H, Ikuta K, Tsuchida M, Hoshi Y, et al. Outcome of 154 patients with severe aplastic anemia who received transplants from unrelated donors: the Japan marrow Donor Program. Blood. 2002; 100:799-805. [PubMed: 12130489]

81. Deeg HJ, Seidel K, Casper J, Anasetti C, Davies S, Gajewski JL, Territo M, Ramsay N, Harris RE, Castro-Malaspina $\mathrm{H}$, et al. Marrow transplantation from unrelated donors for patients with severe aplastic anemia who have failed immunosuppressive therapy. Biology of Blood and Marrow Transplantation. 1999; 5:243-252. [PubMed: 10465104]

*82. Viollier R, Socie G, Tichelli A, Bacigalupo A, Korthof ET, Marsh J, Cornish J, Ljungman P, Oneto R, Bekassy AN, et al. Recent improvement in outcome of unrelated donor transplantation for aplastic anemia. Bone Marrow Transplant. 2007This retrospective study attributes the better outcome of unrelated donor transplantation in recent years to better supportive care, in particular the routine use of high molecular HLA typing for donor selection.

*83. Kennedy-Nasser AA, Leung KS, Mahajan A, Weiss HL, Arce JA, Gottschalk S, Carrum G, Khan SP, Heslop HE, Brenner MK, et al. Comparable Outcomes of Matched-Related and Alternative Donor Stem Cell Transplantation for Pediatric Severe Aplastic Anemia. Biology of Blood and Marrow Transplantation. 2006; 12:1277-1284. [PubMed: 17162209] In this small retrospective study, outcome following alternative donor stem cell transplantation was reported to rival that of matched sibling donor transplant in pediatric patients.

*84. Maury S, Balere-Appert M-L, Chir Z, Boiron J-M, Galambrun C, Yakouben K, Bordigoni P, Marie-Cardine A, Milpied N, Kanold J, et al. Unrelated stem cell transplantation for severe acquired aplastic anemia: improved outcome in the era of high-resolution HLA matching between donor and recipient. Haematologica. 2007; 92:589-596. [PubMed: 17488681] This retrospective study shows that survival after unrelated stem cell transplantation for SAA has improved significantly over the past 15 years. The better survival was attributed to better donor selection due to high-resolution HLA matching. Results for young patients who are fully HLA- 
matched at the allelic level with their donor were comparable to those observed after a matched sibling donor.

**85. Deeg HJ, O'Donnell M, Tolar J, Agarwal R, Harris RE, Feig SA, Territo MC, Collins RH, McSweeney PA, Copelan EA, et al. Optimization of conditioning for marrow transplantation from unrelated donors for patients with aplastic anemia after failure of immunosuppressive therapy. Blood. 2006; 108:1485-1491. [PubMed: 16684959] In previously treated AA patients, this study shows that a minimal dose of $200 \mathrm{cGy}$ total body irradiation is required to achieve successful engraftment of unrelated donor marrow when added to antithymocyte globulin + cyclophosphamide conditioning.

86. Bacigalupo A, Locatelli F, Lanino E, Marsh J, Socie G, Maury S, Prete A, Locasciulli A, Cesaro S, Passweg J. Fludarabine, cyclophosphamide and anti-thymocyte globulin for alternative donor tranplants in acquired severe aplastic anemia: a report from the EBMT-SAA Working Party. Bone Marrow Transplantation. 2005:1-4.

87. Kosaka Y, Yagasaki H, Sano K, Kobayashi R, Ayukawa H, Kaneko T, Yabe H, Tsuchida M, Mugishima H, Ohara A, et al. Prospective multicenter trial comparing repeated immunosuppressive therapy with stem cell transplantation from an alternative donor as secondline treatment for children with severe and very severe aplastic anemia. Blood. 2007 blood-2007-2008-099168. 